\title{
How to Win the Evolution War: Teach Macroevolution!
}

\author{
Kevin Padian
}

Published online: 10 March 2010

(C) The Author(s) 2010. This article is published with open access at Springerlink.com

\begin{abstract}
If the American public understood what is actually known about the major evolutionary transitions in the history of life and how we know about them, uncertainty about evolution would drop precipitously, creationist arguments would fall on deaf ears, and public education in biology would make much more sense than it now does. Macroevolution must take a much more prominent place in K-12 science teaching. To do so, a curriculum must be redeveloped at both $\mathrm{K}-12$ and college levels, so that preparation in macroevolution is a required part of K-12 biology preparation.
\end{abstract}

Keywords Creationism · Evolution · Macroevolution ·

Evolution education $\cdot$ Intelligent design

The war of entrenchment and retrenchment in American public schools has gone on long enough. Pendulums swing; yearly skirmishes result in gains and losses for each side, often in the same state; just when the last bunch of anti-intellectuals has been voted off the school board, along comes another group to take their places. It's educating a parade, as Genie Scott often says. But it's time for the parade to get smarter.

We are fighting the same battles over and over again. ${ }^{1}$ To change this, evolutionists have to shift the ground. For too long scientists and educators have been on the defensive, trying to preserve the teaching of the same K-12 canon that is keeping the populace ignorant about how evolution works in the long run and how we know about it. Make no mistake:

\footnotetext{
${ }^{1}$ This language may seem overly pugnacious, but I'm deliberately borrowing it from the creationists, who have used the "battle" and "war" metaphors incessantly for over half a century (Numbers 2006).

K. Padian $(\bowtie)$

Department of Integrative Biology and Museum of Paleontology,

University of California,

Berkeley, CA 94720-3140, USA

e-mail: kpadian@berkeley.edu
}

what most worries creationists is that the average $\mathrm{K}-12$ student will learn about how we know about the major transitions in the history of life. Currently, the system works for the creationists, and for four main reasons. First, nothing substantial about macroevolution is in the framework or syllabus of any state, so not only will it not be taught, it will be discouraged from being taught. Second, very few evolutionary biologists have a first-hand understanding of macroevolution, and they do not spend substantial time on it in their college courses. This is because most of them are population biologists and population geneticists, and they have had little or no training in macroevolution. Third, as a result, college biology students, including those who become teachers, have a very poor background in macroevolution. And fourth, for all these reasons, textbooks in all grades from K-16 fail completely to convey an understanding of how evolution works in the long run.

In this essay, I want to explain why a full and straightforward exposition of macroevolution in seventh-grade lifescience texts, high school biology texts, freshman-level college biology texts, and upper division texts in evolution and related subjects is the single most effective advance that can be made in educating the public about evolution. This means convincing a large proportion of that "undecided" or uneducated middle portion of the American spectrum about Darwin's principles of common descent and diversification of life through time. State curricula have to be revised; textbooks have to be rewritten; teachers have to be better educated; and selection committees at the state and local level have to insist on these improvements. I do not pretend that this will be easy; I do not suggest that we stop teaching, teach less of, or de-emphasize what we are already teaching about evolution; I do not say that no one anywhere is doing any of this. I am saying that much more of it has to be done, and it has to be instituted far more strongly. This work has to start now, and on several fronts at once. 


\section{What is Macroevolution?}

Macroevolution means the patterns and processes of evolution above the level of populational change and differentiation. These patterns and processes follow upon speciation events. What that means, in effect, is that speciation - the production of new species-is the raw material of macroevolution, just as the production of new mutations is the raw material of change at the population level. Of course, once species are separated by speciation events, they still contain populations, and these populations generate mutations that continue to be the raw material of further evolutionary change that separate the sister species even more. The important thing is that when we talk about macroevolution we are discussing the patterns and processes that happen using species and other larger clades (groups comprising related species) as the units in play-not individuals in populations with gene flow and shifts in allele frequencies. The difference between micro- and macroevolution is much like the difference between how your town votes in an election and how the whole country votes: there are lots of agendas in different regions that don't play out on every local stage, and how your town votes is not a necessary predictor of how the nation votes. That's what keeps political scientists busy. And the relationships-which are not necessarily fractal-between microand macroevolution keep evolutionists similarly busy.

Examples of macroevolutionary events, processes, and patterns would include the rise of the dinosaurs (and their extinction); how grasses came to dominate most continents, and how mammalian herbivores responded; how flight evolved in insects, pterosaurs, birds, and bats; and why artiodactyls (even-toed ungulates) replaced perissodactyls (odd-toed ungulates) increasingly during the Tertiary Period. These phenomena cannot be predicted just from knowing about Hardy-Weinberg equilibria, runaway sexual selection, or the "rare male effect," important though all those are to some populations of living organisms.

The reason why we study macroevolution as a separate subject from population biology is that the things that happen at the population level do not translate very predictably to the level of the clade. They are different hierarchical levels, as Niles Eldredge, Stephen Jay Gould, and many other paleontologists have pointed out for decades (e.g., Eldredge 1985). It is not that these levels are inconsistent or incompatible. It is simply that what happens at one level does not predict or describe what will happen at the other. Imagine a species of deer in which individuals in populations in some areas are favored because they can forage more efficiently for food in winter, whereas individuals in other populations elsewhere are favored because they can elude predators more effectively. These are interesting phenomena at the populational level, but they do not predict why cervids (the deer family) are far less diverse and numerous than bovids (the antelope family) - which they have been for the latter part of the Age of Mammals.

Analogies are tricky, but hierarchical concepts work much the same in evolution and economics. There are many facets to microeconomics and macroeconomics, just as to microevolution and macroevolution. Let's consider some simple ones. Microeconomics could describe the operation of mom-and-pop groceries, supply and demand of small companies, and economic interactions in relatively selfcontained towns or principalities. Macroeconomic topics would include international monetary policy, the Federal Reserve System, and questions of wage and price controls. In both macro and micro senses, there is a common currency. It is-well, currency. Dollars, that is. It unites the levels, even though the problems are very different. In evolution, genetics is the common currency: that is, genes. Populations of a species share a genetic currency that allows interchange and evolution of the genetic and phenotypic structure of a lineage; above the species level, the genetic material is hardly ever interchanged, but within distinct lineages it continues to evolve and differentiate them.

Here are five components of macroevolution that every student of biology should understand:

1. The rates of origination and extinction of species shape the history of life. These rates are exactly analogous to the interplay of births and deaths in populations, which structure the history of these populations through time. Because in a population there will always be deaths (extinctions at the species level), the birth rate (speciation rate) must keep up with the death rate (extinction rate) on average through time or else the population (clade) will die out (become extinct). Population size (diversity of species in a clade) can decrease for two reasons: the birth rate (speciation rate) can decline or the death rate (extinction rate) can increase. (Conversely, the diversity of species in a clade can increase either because the speciation rate increases or the extinction rate decreases.) In macroevolution, we see both processes and all four combinations of patterns shaping the diversity of clades through time.

2. As a species-lineage evolves, its morphology may change in many ways or hardly at all. The bestdocumented fossil sequences show a variety of modes of evolution. Some - actually very few-change in a slow and steady directional way. A great many show statistically minor fluctuation of features in one direction and then another, but generally centering around a fairly steady mean. Others show almost no change at all for most of their histories, then substantial change in a very short period of time. When we can see these lineages separate into two distinct lines in the 
fossil record, we are witnessing a speciation event. Otherwise we are witnessing morphological change within lineages, which should reflect genotypic and ecophenotypic influences. The main question we should be asking in evolutionary biology — but we are not, because most of us already think we know the answer - is whether the kinds of changes we see within generations of living populations, and the models we use to predict and describe long-term change-actually reflect the paleontological data or are largely irrelevant.

3. Extinctions are studied at two levels: background and mass extinctions. The extinctions that are more or less constantly occurring throughout the history of life are called background extinctions, and their levels have been fairly regular over the last 500 million years or so. Occasionally - five times during that period - the number of extinctions in a relatively short period of time has spiked so high that a different concept, and usually a different cause (or causes), is required to explain it. We call these mass extinctions.

To understand whether an event is really unusual, paleontologists can chart rates of origination and extinction for the intervals of time preceding and following the event in question. The numbers for the event in question can then be statistically compared to these normalized patterns to determine whether it is statistically different, and which component (origination or extinction rate, or both) merits explanation. In this way, the locus of extinction can be circumscribed - to a particular area (the Indian Ocean), group (trilobites), habitats (the coral reef community), or time intervals (the Famennian stage of the Devonian Period). Discussions of whether we are now in a "sixth extinction" are senseless without this methodological perspective.

4. Phylogenetic analysis documents the evolution of life. Just charting which critters lived at which times during the history of life is a chronicle with little structure. This chronicle can be looked at in ecological termsfor example, how nearshore and offshore marine communities have changed through time, or how mammals and their relatives have competed for dominance with reptile groups on land. But just talking about these broad ecological and taxonomic categories tells us little about the processes of evolution itself. For that, we need to look at individual clades, and we need the independent method of phylogenetics (cladistics) to construct that genealogical backbone. Against this pattern, we can test our hypotheses of evolutionary processes and how we think they may have shaped the history of life. There is no space here to explain phylogenetic analysis, but there are many freely available and accessible sources (e.g., http://evolution. berkeley.edu/evolibrary/article/phylogenetics_01).
5. We know a tremendous amount about how major groups of organisms originated, how major new adaptations evolved, and how fundamental ecological shifts took place in the great lineages of plants, animals, and other creatures throughout the history of life. This, I will argue, is the most important of all these concepts that needs to be conveyed to students. Using the integration of information from fossils, genetics, developmental biology, embryology, and phylogenetics, we can now say confidently that we have limned the major outlinesand many important details - of great evolutionary events such as the Cambrian explosion of animal life, the origin of tetrapods, the rise of dinosaurs and the evolution of birds and their flight, the origin of mammals, the origin of whales, and many others. This was the subject of most of my testimony in the Dover "intelligent design" trial in 2005, and you can read and see what we presented to the judge at http://www2. ncseweb.org/kvd/exhibits/Padian/Padian_transcript. html. Ken Miller, who held up the other end of the science on the plaintiffs' side of the trial, spoke just as convincingly about how we know that the bacterial flagellum had structural and functional antecedents among other simpler bacteria, how we know about the evolution of the human immune system, and why humans have two fewer chromosomes than other apes simply because two pairs fused in the course of human evolution (and so contain two centromeresone functional, the other not) (see http://ncseweb.org/ creationism/legal/kitzmiller-trial-transcripts). This $m a-$ terial is not straightforwardly explained in American textbooks and state curricula, and it is what creationists are most afraid of having schoolchildren understand. How this situation came about is the subject of the rest of this essay.

\section{Teaching for Literacy Instead of Increased Specialization}

When the Russians launched Sputnik in 1957, the United States went into panic mode about how it trained its students in science and engineering. We were losing the space race and could soon be losing the arms race. Science education was accordingly beefed up. I remember as a seventh-grade student in the early 1960s having our heads crammed with information about plasmids, telomeres, and the Krebs cycle - information for which we had no use and little interest, and most of which was certainly over my head. It gave me a distaste for science that I did not shed until college. Some years after that, when I began to teach $\mathrm{K}-12$ science myself, I realized that in my K-12 experience I had never learned answers to the questions that interested 
me most, such as how the dinosaurs and other extinct creatures evolved, why the sky is blue, what controls the tides, and what causes earthquakes and volcanoes. I had never been taught the names of local plants and animals, never realized how insects are classified, never learned the geologic history of the area where I grew up.

It is of real concern that most students in biology at Berkeley and elsewhere have so little knowledge of such subjects, decades after my own disappointments. By this time in their careers, most of them have already decided to be doctors or optometrists, so the pure interest that these subjects could have generated in them at a younger age has been extinguished and replaced by a purely professional drive. It doesn't help that the Regents of the University of California do not count Earth Science toward the three years of science required for admission. This is particularly ironic given that Earth Science comprises geology, astronomy, oceanography, and meteorology — all subjects that are of extreme practical value for Californians, and all of which bear on issues that at one time or another will show up in the voting booth! $!^{2}$ (In contrast, it's difficult to conceive of propositions regarding physics and chemistry on the ballot.) Other states are similarly benighted.

This is the problem of teaching for specialization instead of literacy. Education is driven top-down: that is to say, most of what students are taught at one level is meant to prepare them to be taught more complex concepts at the next higher level. This is teaching for specialization, as if all our students were going to be professional chemists, physicists, or molecular biologists. ${ }^{3}$ This is how curricula are designed in the United States, to the extent that they are designed at all. Is it any wonder that our students score so

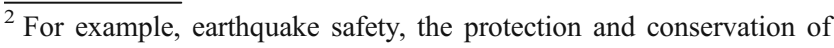
watersheds, ocean circulation and pollution and the effect on marine life and fisheries, the wisdom of building houses on unstable cliffs and historic floodplains, population growth with respect to hydrologic resources and supplies, El Niño fluctuations and civic emergency preparedness, and the quality of information likely to proceed from a proposed NASA space probe.

${ }^{3}$ The problems are not confined to science education. Schools no longer teach civics, which was a practical curriculum in American institutional life that courses in history did not teach. For three generations, most of our citizenry have not been able to explain the separation of powers established by the Constitution, and we have all seen the polls that show that most Americans disagree with the propositions that comprise the Bill of Rights. They cannot balance a checkbook and do not understand how banks work or how interest is compounded. They do not understand the difference between a democracy and a republic (and which form of government is that of the US), why there are two houses of Congress, why the Supreme Court doesn't make laws, why the President can't do anything he wants to, why Nazis can organize marches in American streets but you can't yell "Fire!" in a crowded theater, and why the right to bear arms was an important right for the first Americans but it does not mean that anyone has a right to bring any kind of gun anywhere he wants to.
}

poorly on standardized tests compared to students from most developed nations, even though a high-school biology book weighs eleven pounds (five kilograms) and is crammed with bold-faced terms and concepts to memorize?

An alternative approach, and one that would not necessarily present an entirely different body of information, would be to ask what students need to know in order to be informed citizens, and to put the highest priority on teaching that first at every grade level. Knowledge that is more specialized, and that would lead to careers in organic chemistry, molecular biology, and particle physics could be introduced as time and grade-appropriate level permitted. But first it is important to decide what information is critical for literacy. ${ }^{4}$ It is obviously not the goal of this paper to establish this for all of science or even for biology. But consider this: if the vast majority of Americans, including the $25 \%$ or so that identify themselves as conservative, evangelical, or fundamentalist Christians, assert that scientists have no evidence for the emergence and evolution of new major groups of organisms and their adaptations, and another $40-50 \%$ or so of Americans just don't know one way or the other, shouldn't a major goal of biological literacy be to educate American students about our evidence for these things?

This concept is expressed in Fig. 1 as a pair of inversely oriented, overlapping "cones of content," the most fundamental of which is literacy, and the more secondary of which is specialization of knowledge. The need for literacy is never lost, but it should be cumulative, so more complex concepts of literacy can be developed at higher levels. Specialization of knowledge can increase accordingly.

\section{What's in the Textbooks and Why It's Not Doing the Job}

Any proposal to spend more time on a new subject is greeted with the quite reasonable objection, "but what will we eliminate in order to do that?" There will be howls, but here are some space-wasters that can easily go.

First of all, Lamarck. His worldview was really of another time, far more complex and nuanced than can be conveyed in a life science or biology text in the space available. What Lamarck thought-including his whole "system" of fluids governing all aspects of natural phenomena - is difficult to describe, and anyway, he was wrong and his ideas are almost forgotten. (Some years ago in Paris, I found that his Philosophie Zoologique was out of

\footnotetext{
${ }^{4}$ Equally important is teaching students at all grade levels, but especially the early ones, to love science, so subject matter should not only be grade-appropriate and keyed to major concepts, but also of high potential interest to students, if it is to be maximally effective.
} 
Fig. 1 Through the grades, emphasis on scientific literacy is initially paramount, but as literacy becomes well founded, specialized knowledge can be introduced. This is in contrast to a system where all knowledge is transmitted simply as "watereddown" concepts of specialized knowledge

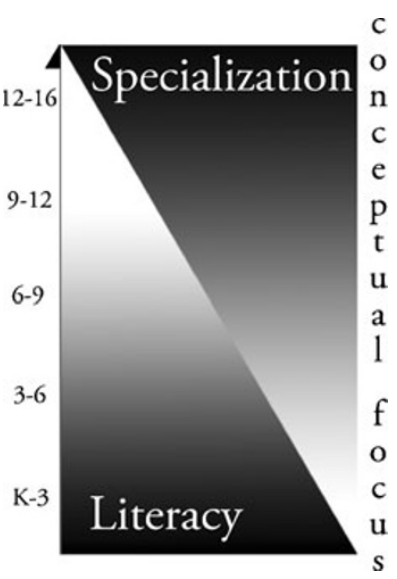

print.) His career and Darwin's did not overlap, and each of them spent exactly one paragraph among thousands of printed pages on the neck of the giraffe; yet this example is trotted out in the vast majority of biology texts, as if they debated each other head-to-head. There is not a single textbook in America that gives an accurate account of what Lamarck was talking about. This is sufficient reason in itself to eliminate him from the books.

Second, species concepts. Each of them is only provisionally useful, and none embodies Darwin's perspicacity in the first chapter of the Origin of Species (1859). Darwin recognized that naturalists, despite their confidence, could not make any universal statements that enabled others to determine what a species was, or to differentiate it from a subspecies, a genus, a race, or a variety. This is because lineages (to use a neutral term) are constantly in the process of diverging from each other and are at different stages in the process, so the divisions that we call races, subspecies, species, etc. are arbitrary points on a continuum. And moreover, different kinds of organisms speciate in different ways, so one species "concept" cannot fit all. Emphasize the ideas in the previous three sentences, and there is no need to wade through the morass of "species concepts." Different "species concepts" provide helpful diagnoses of differences among species, but they distract attention from the process of speciation, and they should not be pitted against each other as exclusive alternatives.

Instead, the process of speciation, as it occurs in many ways in many different groups (genetically, ecologically, geographically) should be described and documented pluralistically. The formation of new species is the first step to macroevolutionary patterns and processes, so it is all the more germane to the thesis of this paper.

Third, superficial glosses on the history of life that take three pages and mostly recount an aleatory assortment of factoids about groups that "appeared" and "disappeared" along with climate changes that seemingly have magical causes. This pablum is of no conceivable use. A sensible annotated chart of geologic time can give an overview of the history of life; it has been standard since Richard Owen's (1860) text Palaeontology. Use the rest of the space to document examples of how we know what we know about the evolution of some major groups and adaptations.

Fourth, Linnaeus and his classificatory system. Linnaeus had no classificatory philosophy;" his "Natural System" was an attempt to know the mind of the Creator, which is not a goal of modern science. He grouped by similarity and worked a century before the greatest idea in biology even began to be generally accepted. He invented some rank names and promoted the binominal system (unique genus and species name). But his influence on biological education has always been greater than it should be. In the Origin of Species, Darwin insisted that all classification should be based on genealogy-what we would call phylogenetic relationship. No one listened; they kept using Linnaeus's system, so we had another century of taxonomic stagnation until that was reformed. Essentially all modern systematics is phylogenetic (cladistic), and the Linnean "ranks" such as Order and Class are nothing more than bookmarks with no biological comparability or meaning. They have outlived their utility, and it is a waste of space to rehearse Linnaeus' history and system beyond the few facts above.

On the other hand, it is surprisingly useful to teach students phylogenetics before the units on evolution and diversity of life. All students have some experience with types of plants and animals, and they know that organisms are related to each other; they just don't know how this is determined. Show them that part first, and then they can understand, for example, why we classify birds within the reptiles (instead of as a separate "Class"), and why we don't classify even-toed and odd-toed hoofed mammals together (as "Ungulata"), even though they have hooves.

\section{What the Creationists Don't Want Students to Know}

It may be surprising to learn that fully half of the creationist "textbook" Of Pandas and People, which the Dover (PA) school board wanted to replace Miller and Levine's standard high-school biology textbook, is devoted to disparaging the evidence for macroevolution, including what is known of the Cambrian explosion, the emergence of tetrapods onto land, the origin of birds, the evolution of mammals, and the origin of whales (Padian and Matzke 2009). The book, moreover, teaches children that homology is just a circular notion, that the act of classifying the

\footnotetext{
5 This is an overstatement, of course, but his rationale for classification makes no more sense to today's science than Aristotle's four causes do.
} 
Tasmanian wolf with the marsupials instead of with the placental wolf and dog is essentially a philosophical choice, and that there are no transitional stages between any major groups of organisms - that "by and large" this is just something that "Darwinists believe."

Why are creationists so adamant in denying evidence that we have had for decades? Because if they allow that there are transitions among major groups, their entire cause is lost. They must fight this at any cost. If schoolchildren are allowed to understand what we know about the subjects in the paragraph above, and how we know about them, they might accept the evidence for evolution. Nothing else-not Hardy-Weinberg equilibrium, not species concepts, not directional selection, not allopatric speciation theory-will convince students so thoroughly and vividly that what seems so improbable on the surface, and what seems to be so easily explained by the special creation of all major groups of organisms, is belied by a body of evidence that scientists have exhumed in the course of less than two centuries (Futuyma 2009).

Consider "intelligent design," the latest morph in the evolution of creationism. Most of its oeuvre has been devoted to criticizing evolutionary science (e.g., Wells 2001; Johnson 1991; etc.), like its ancestors "BibleScience" and "Creation-Science." To the extent that it has anything positive to offer as substance of "intelligent design," two concepts have been advanced. The first is Michael Behe's (2006) "irreducible complexity," a concept not original to him, and the second is William Dembski's (1998) "complex specified information," essentially an attempt to attach probabilities to the former notion. Irreducible complexity insists that some "adaptive packages" (to use the language of Pandas) are too complex to have evolved step-by-step by natural means. This is a flat a priori denial of macroevolution in the sense of the evolution of major new groups and adaptations. It is a specific denial of exaptation (Gould and Vrba 1982), the idea that a structure that appears never to have had a function could acquire one under changed circumstances, and of secondary adaptation, the idea that a structure with a given function could acquire a second function (or more), and even come to use the new one(s) more than the original. ${ }^{6}$ This has been a theme of creationism long before its recent incarnation as ID (Matzke et al. 2006). ID proponents and other creationists must do everything they can to prevent students from learning what is known about these topics. This by itself is the principal reason to give macroevolution the foremost prominence in biology textbooks.


slightly different.
}

\section{How to Teach What we Really Know about Evolution}

Elsewhere (Padian 2008), I have described the use of evograms, diagrams that show students how we know what we know about the origins of major evolutionary groups and adaptations. These diagrams convey a variety of independent kinds of evidence and put them in explicit evolutionary - that is to say, phylogenetic, context. In Fig. 2 is an already classic example of the emergence of tetrapods (which should not be called the "fish-amphibian transition"). The top row of figures shows photos and drawings of the actual specimens on which our understanding is based. The row of drawings beneath this represents the comparable (homologous) skeletal elements, based on position, histology, and development (the same criteria of homology used by pre-Darwinians). Below this is a cladogram of the animals in question, based on dozens of features from all parts of the skeleton (so the arrangement is not circular). Underneath all this are liferestorations of the animals, to form a basis for discussion of lifestyle and ecology. The reduction of digits from eight to five (and fewer) clearly emerges as an evolutionary pattern, one of many in the evogram.

This kind of diagram, when properly explained and annotated, shows students what we know and how we know it. We interpret the morphology of fossil and living organisms to help us identify how individual body parts have changed in shape and function in lineages over time. The relationships of those lineages are understood by a logically independent process of phylogenetic systematics. We can add information from developmental genetics, embryology, stratigraphy, and other fields as useful. Properly explained, this kind of representation is immune to creationist charges that we are making up stories by arranging the fossils to suit our preconceived notions. Scientific explanations can be presented as exercises in consilience, the mutual testing of independent lines of evidence that purport to explain natural phenomena (Whewell 1858; Wilson 1998).

\section{How the Science Education Industry Works}

But how will these advances be instituted? Consider first that the United States, almost alone among developed nations, does not have a centralized curriculum-in any subject. The reasons are historical and political and beyond discussion here. Instead, the 50 states have state curricula, which correspond generally to some degree, but are deeply different especially when it comes to "controversial" topics such as evolution (a report for the Fordham Institute written by Lawrence Lerner, plus other related documents, can be found at http://www.edexcellence.net/issues/results.cfm? withall=lerner). The state curricula are developed in various 


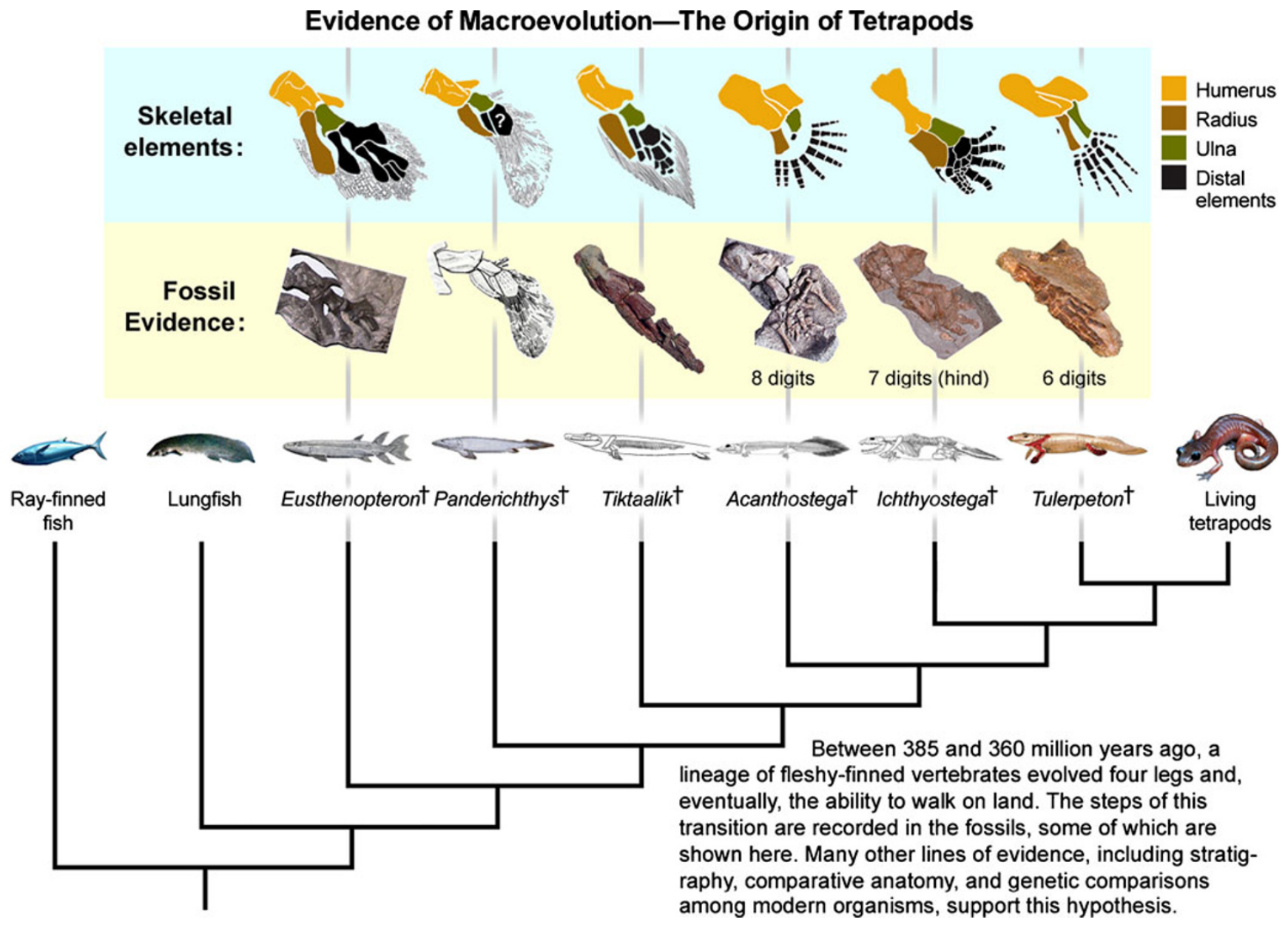

Fig. 2 An "evogram" depicting the origin of tetrapods. For explanation see text

ways, usually by teachers and other educational administrators, occasionally with input from scholars (although this input is often after the fact and contentious, a reaction to perceived shortcomings and inaccuracies).

In 23 states, committees are convened to evaluate textbooks and other instructional materials against a set of standard criteria that include not only the quality of the academic content but also paper and binding quality, amount of white space, reading level, and representation of various demographic groups (and often state history and culture). Instructional programs that pass muster and are "adopted" may be "selected" by local districts, sometimes with the stricture that state monies can only be spent on adopted programs.

Because local standards differ, publishers are in the position of trying to satisfy everyone at once. It is expensive to produce several different editions for different parts of the country, so publishers are happiest when major players in the adoption game endorse a version that can be widely sold. Sadly, publishers often get dunned as much for providing too much information (and often better content) as for too little. I do not want to give the impression that publishers are any better or worse than they have to be; they are businessmen. Often, different elements of their companies have conflicting goals. The editorial staff may wish to produce books with better scientific content, while the sales staff is berating them for putting in "too much evolution" that makes it difficult to sell the programs in some districts.

Such is the system, briefly, in America. It is complex, with many independently working parts, and no universal formula for success. The inertia of this system, partly the result of its sheer size and lack of explicit coordination and centrality, makes it highly resistant to change.

\section{Three Ways to Change the System and Improve Evolution Education}

First, improve the standards for adoption in the states and districts that matter most. Concentrate the push for improvement where the greatest number of sales will be made-large adoption states such as California, Texas, and New York. Scientists, working with state science teacher 
organizations (and this is critical), can get placed on committees that draft state standards, frameworks, curricula, and other documents, as well as adoption panels. Scientists will have to get used to doing more listening than talking, expecting and settling for incremental change, doing a lot of glad-handing and other political activities for which they have not been trained, and digging in their heels for a long and difficult struggle. Have no illusions that expertise or intellectual merit will be respected everywhere. But be confident that although politics can trump the best intentions, better politics can prevail.

Second, in the absence of a national curriculum, establish a de facto one. The American Association for the Advancement of Science (AAAS) produced Science for All Americans (Rutherford and Ahlquest 1991), a manifesto of how good science education could be structured. The resources and influence of scientific societies such as the AAAS and the National Academy of Science, which advises Congress and the President on scientific matters, should be harnessed to this greatest of all scientific challenges.

Third, get better coverage of macroevolution into college textbooks. Currently this coverage is dismal to non-existent in introductory biology and in upper division evolution, paleontology, and comparative anatomy textbooks (Padian 2008). University professors are the main customers of these books; they assign them to their students. This proposed reform will not work until and unless professors object vocally to editors, publishers, and authors (many of whom are colleagues in their fields) that macroevolution has to get stronger representation. (And of course, they have to change their own curriculum to reflect this.) Properly instituted, an appreciation of macroevolution should inhabit many aspects of a typical biology course, from physiology to systematics.

The reason why it is so important to get more macroevolution into the college level textbooks first (without giving up the push at K-12) is because these concepts will not be taught at K-12 unless they are required knowledge for the college level. Remember the dictum explained above: education is driven top-down. Most of what students are taught at one level is meant to prepare them to be taught more complex concepts at the next higher level. This is why it is vitally important to begin this push at the college level, and to make it clear to K-12 publishers that macroevolution is an essential component of biological education.

\section{What Teachers Can Do}

Teachers, of course, are caught constantly between the duty to teach good curricula and the pressure from some parents, clergy, and others to downplay evolution and other elements of good science. Most teachers are not content experts; when I taught public school science I continually felt the insecurity of needing to know more and not feeling able to master this knowledge. The availability of science courses at times that I could take them was really limited, and eventually this drove me to leave $\mathrm{K}-12$ teaching and return to graduate school. Many teachers with whom I have spoken over several decades have confirmed their own experience.

The first recommendation, therefore, is that teachers enlist scientists on their side. Please don't feel that scientists will think your knowledge is deficient; they understand that your job is different (even if, like most teachers, they feel the urge to lecture and teach constantly). They can help articulate explanations for why good integrative science needs to be taught, and they can help to evaluate the quality of science content in your instructional materials. And don't be thin-skinned! Scientists are used to teaching college students who are drilled with the very latest knowledge. You were once one of those students, and given some sympathetic coaching, you can match any of them.

The second recommendation is not to support the purchase of instructional materials that are conceptually inferior. Demand good science. Textbook salesmen have to sell at the local district level in most states; yet most local districts place little weight on the science content when evaluating textbooks, because they assume that state agencies and the companies' reviewers have done that for them. This is a poor assumption, because real science expertise is poorly represented on most state adoption panels (when they exist).

The third recommendation is to become involved with state science teacher organizations and make this a greater issue. Anyone who has been to one of their annual conferences has to be impressed at the presence of textbook companies and their salesmen, editors, and authors. This is the time to impress all of them with the need for better coverage of evolution, particularly macroevolution.

\section{Conclusion}

For decades this problem has been staring us in the face: creationists are fine with microevolution (changes within populations), because they just see it as noise in the system, variation within created kinds. But they abhor macroevolution because it implies that major groups can evolve from other major groups, there is a continuum of life, and therefore even humans might be part of that continuum.

It has not been much appreciated until now how deficient our textbooks and instructional materials are in explaining to students how we know what we know about macroevolution, the patterns and processes that describe the 
major changes in the history of life. There is no reason at all to develop this in textbooks so as to convince the $25 \%$ of our populace who are fundamentalist Christians of the reality of large-scale evolution. This effort is about the 40 $50 \%$ of people in the middle, who are reasonable and uncommitted, but otherwise uneducated about the problem. If they are able to understand how we know what we know about macroevolution, creationists are further marginalized as irrational and unreasonable. I hesitate to hope for this, but I think there is a substantial possibility that a lot of our sociopolitical problems will diminish, and I point to the prevalence of acceptance of evolution in other developed countries as evidence (Miller et al., 2006). And the story of evolution as we present it to students will become more and more interesting and meaningful.

Acknowledgments Among the giants who have educated the American public about evolution-all in different ways-we can number Asa Gray, Thomas Henry Huxley, Henry Fairfield Osborn, and Stephen Jay Gould. One can go on and on to mention E.H. Colbert, Doug Futuyma, Niles Eldredge, Carl Zimmer, and a host of others. Genie Scott has done at least as much as any of them. Over four decades she has devoted her life to clarifying what evolution is and what science is (and is not) for teachers, parents, school board members, education department staffs, governmental officials, reporters, writers, documentary producers, and many other kinds of people. Her approach has always been to calm the waters, to explain how to get along, to avoid conflict, to explain, to clarify, to negotiate. No one not directly affiliated with the National Center for Science Education can conceive of how many "flare-ups" and potential conflagrations she and her staff have helped communities avoid, how many pilgrims have been enlightened by her knowledge and advice, how many unfortunate misunderstandings and even lawsuits have been averted by her counsel. Genie, this country owes you a debt that it can never repay.

I thank Brian Swartz, the originator of the "tetrapod" evogram of Fig. 2, Meriel Melendrez, who produced Fig. 1, and all the other graduate students who contributed material to the presentation I gave at the Dover trial: Liz Perotti, Jann Vendetti, Randy Irmis, Jenny McGuire, Nick Pyenson, and Andrew Lee; Nick Matzke, for being a constant and tremendous resource; Glenn Branch and the whole
NCSE staff; Vic Walczak, Eric Rothschild, Steve Harvey, Chub Wilcox, Tom Schmidt, and all our other legal eagles from the Dover trial; and Ken Miller, Brian Alters, Rob Pennock, and Barbara Forrest for always being there. This is UCMP Contribution No. 2014.

Open Access This article is distributed under the terms of the Creative Commons Attribution Noncommercial License which permits any noncommercial use, distribution, and reproduction in any medium, provided the original author(s) and source are credited.

\section{References}

Behe MJ. Darwin's black box: the biochemical challenge to evolution. New York: Free Press; 2006.

Dembski WA. The design inference: eliminating chance through small probabilities. Cambridge: Cambridge University Press; 1998.

Eldredge N. Unfinished synthesis: biological hierarchies and modern evolutionary thought. New York: Oxford University Press; 1985.

Futuyma D. Evolution. 2nd ed. Sunderland: Sinauer; 2009.

Gould SJ, Vrba ES. Exaptation: a missing term in the science of form. Paleobiology. 1982;8:4-15.

Johnson PE. Darwin on trial. Washington, DC: Regnery; 1991.

Matzke N, Gross P. Analyzing critical analysis: the fallback antievolutionist strategy. In: Scott E, Branch G, editors. Not in our classrooms: why intelligent design is wrong for our schools. Beacon Press; 2006. pp. 28-56.

Miller JD, Scott EC, Okamoto S. Public acceptance of evolution. Science. 2006;313:765-6.

Numbers RL. The creationists: from scientific creationism to intelligent design. Cambridge: Harvard University Press; 2006.

Padian K. Trickle-down evolution: an approach to getting major evolutionary adaptive changes into textbooks and curricula. Integr Comp Biol. 2008;48:175-88.

Padian K, Matzke N. Darwin, Dover, "Intelligent Design", and textbooks. Biochem J. 2009;417:29-42.

Rutherford FJ, Ahlquest A. Science for all Americans. New York: Oxford University Press; 1991.

Wells J. Icons of evolution: science or myth?: why much of what we teach about evolution is wrong. Washington, DC: Regnery; 2001.

Whewell W. History of scientific ideas. Being the first part of the philosophy of the inductive sciences. London: J.W. Parker; 1858.

Wilson EO. Consilience: the unity of knowledge. New York: Alfred A. Knopf; 1998. 